\title{
AMPA, Kainate, and Quisqualate Activate a Common Receptor- Channel Complex on Embryonic Chick Motoneurons
}

\author{
Charles F. Zorumski ${ }^{1,2}$ and Jay Yang ${ }^{1}$ \\ Departments of 'Anatomy and Neurobiology and PPsychiatry, Washington University School of Medicine, St. Louis, \\ Missouri
}

The actions of the putative quisqualate-selective agonist $D L-$ $\alpha$-amino-3-hydroxy-5-methyl-4-isoxazole-propionic acid (AMPA) were examined in identified embryonic chick motoneurons using gigaseal recording techniques and compared with properties of the selective non-NMDA excitatory amino acid agonists kainate and quisqualate. Pressure application of AMPA induces an inward going current when neurons are voltage-clamped at negative membrane potentials. The current-voltage relationship for this response is linear with reversal near $0 \mathrm{mV}$. Over the range of $1 \mu \mathrm{M}-10$ $\mathrm{mM}$, the AMPA-induced current is dose-dependent with an $E_{50}$ of $40 \mu \mathrm{M}$. AMPA currents are insensitive to the selective NMDA receptor antagonist, 2-amino-5-phosphonovalerate, and the putative quisqualate selective blocker, glutamate diethyl ester, but are partially inhibited by kynurenic acid. In competition experiments, applications of saturating concentrations of AMPA and either kainate or quisqualate produce responses intermediate between the response to either agonist alone, indicating commonality in the mechanism of these agents. Applications of AMPA with the NMDA-selective agonist aspartate give an additive response.

Analysis of current fluctuations indicates that AMPA, quisqualate, and kainate gate a channel with a primary conductance near 20 pS. Differences in maximal macroscopic current evoked by saturating concentrations of AMPA, kainate, and quisqualate cannot be explained by differences in mean channel open time as the most efficacious agonist, kainate, has the shortest channel open time (AMPA $=\mathbf{5 . 9} \pm 0.4 \mathrm{msec}$, kainate $=2.7 \pm 0.1 \mathrm{msec}$, quisqualate $=5.0 \pm 0.5 \mathrm{msec}$ ). Rather, kainate induces a greater frequency of channel opening. This finding contrasts with results obtained at the nicotinic ACh receptor, where the most efficacious agonists have the longest mean channel open time.

Our results suggest that AMPA acts at the same receptorchannel complex as kainate and quisqualate on chick mo-

\footnotetext{
Received Dec. 17, 1987; revised Apr. 6, 1988; accepted Apr. 7, 1988

This work was supported in part by fellowships from the McDonnell Centers for Cellular and Molecular Neurobiology and Studies of Higher Brain Function C.F.Z. is supported by National Institute of Mental Health Physician Scientist Award MH00630 and a fellowship from the Klingenstein Foundation. We thank Dr. Gerald Fischbach for his support and many helpful discussions and Dr. Laurence Trussell for critical comments on the manuscript.

Correspondence should be addressed to Dr. Charles F. Zorumski, Department of Psychiatry, Washington University School of Medicine, 4940 Audubon Avenue, St. Louis, MO.

Copyright (C) 1988 Society for Neuroscience $0270-6474 / 88 / 114277-10 \$ 02.00 / 0$
}

toneurons and support the hypothesis that only 2 classes of excitatory amino acid receptor complexes exist in this preparation.

The classification of vertebrate postsynaptic excitatory amino acid receptors remains uncertain. Based on agonist action, 3 classes, activated selectively by $N$-methyl-D-aspartate (NMDA), kainate, and quisqualate, are postulated (Foster and Fagg, 1984). Binding studies have cast doubt on this scheme, as only 2 rcceptor classes are found in brain postsynaptic densities (Fagg and Matus, 1984). In postsynaptic densities, kainate and quisqualate bind to the same site.

Previous physiological studies demonstrated that cultured chick motoneurons express only 2 distinguishable classes of receptors for excitatory amino acids (O'Brien and Fischbach, 1986a). One class is activated by NMDA and L-aspartate and is blocked selectively and completely by 2 -amino-5-phosphonovalerate (APV). Agents acting selectively at this receptor exhibit a nonlinear current-voltage relation with decreasing inward current at membrane potentials negative to $-30 \mathrm{mV}$. The nonlinearity is due to a voltage-dependent channel blockade by magnesium ions similar to that reported in other central neurons (Nowak et al., 1984; Mayer et al., 1984). The second receptor class is activated by kainate and quisqualate and is insensitive to APV or magnesium. Agents acting at this receptor exhibit a linear current-voltage relation. Initial studies demonstrated direct competition between kainate and quisqualate over their entire range of effective concentrations and provided no evidence for separate receptors (O'Brien and Fischbach, 1986a).

Ihe synthetic glutamate analog, AMPA, has been reported to act as a selective agonist at quisqualate receptors (KrogsgaardLarscn et al., 1980) and has been used, in some studies, to distinguish between quisqualate and kainate selective sites (Honore et al., 1982; Honore and Nielsen, 1985; Tsai and Lehmann, 1985). These observations led us to investigate the possibility that AMPA might serve as a tool for distinguishing between physiological actions at kainate and quisqualate receptors. We have studied the direct membrane effects of known concentrations of AMPA and other selective non-NMDA agonists under voltage-clamp conditions and report that AMPA exhibits physiological responses similar to kainate and quisqualate, competing with these agents for a common site of action but differing in dose-response characteristics and efficacy. We have also used fluctuation analysis and single-channel recording to investigate differences in maximal response among these agents. A preliminary report of this work has been presented (Zorumski et al., 1986). 


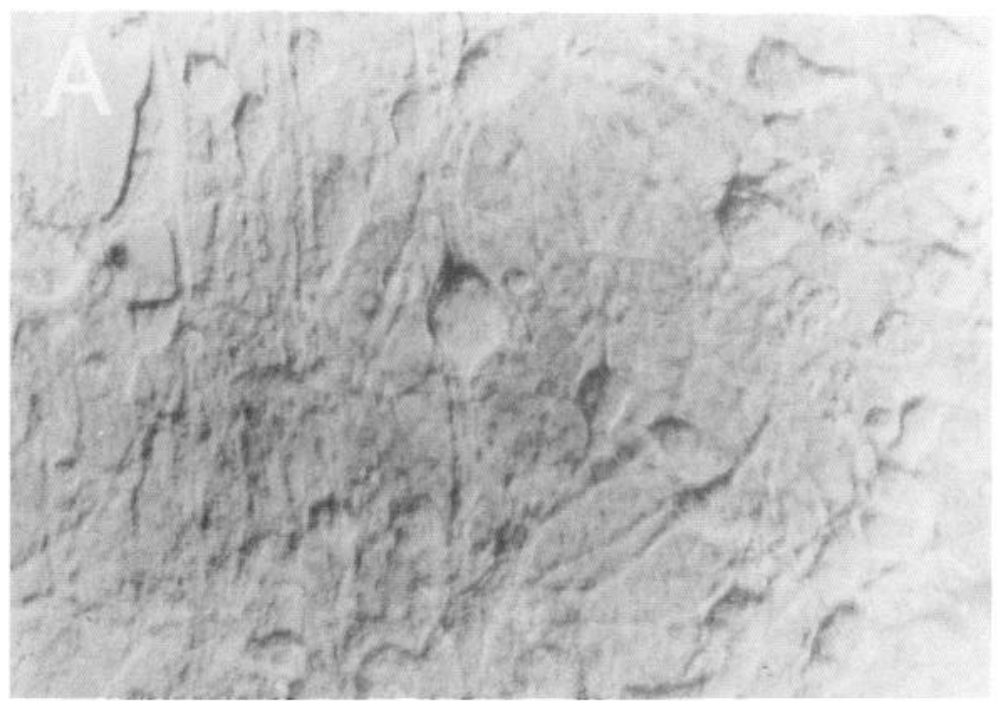

Figure 1. An identified motoneuron grown in culture for $6 \mathrm{~d}$. $A$, Differential interference contrast image of a heterogeneous population of chick spinal cord neurons. $B$, Fluorescent image showing a single rhodamine microsphere containing neuron among the population of cells shown in $A . \times 400$.

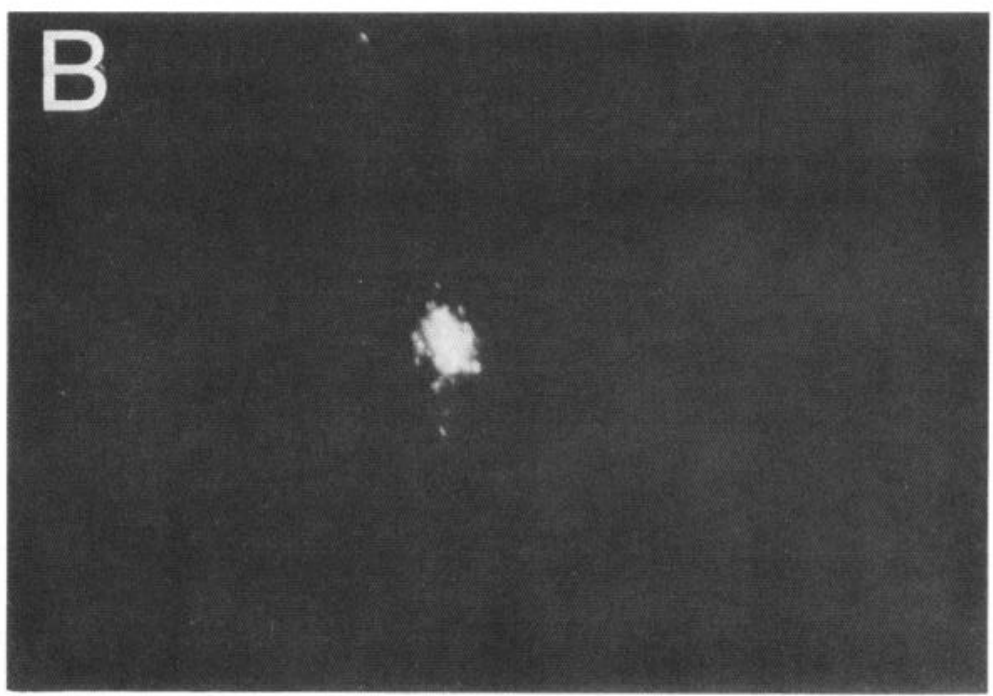

\section{Materials and Methods}

Cell culture and preparation of identified motoneurons. Five-d-old chick embryos were injected in their hindlimbs with a solution containing latex rhodamine microspheres (Tracer Technology, Bardonia, NY) diluted 1:5 with sterile water or isotonic saline (Katz et al., 1984). At 16$24 \mathrm{hr}$ after injection the spinal cords, including the fluorescent labeled motoneurons, were dissociated and grown in primary culture (O'Brien and Fischbach, 1986b). Using this injection protocol we have found that, among spinal cord cells, only neurons in the ventral motor column contain fluorescent label. Cells were plated on collagen-coated glass coverslips cemented to the bottom of Falcon $35 \mathrm{~mm}$ tissue culture dishes into which a 10-15 mm hole was bored. The growth medium consisted of Eagles Minimal Essential Medium (MEM) supplemented with $10 \%$ (vol/vol) heat-inactivated horse serum, $5 \%$ (vol/vol) chick embryo extract (CEE), $200 \mu \mathrm{M}$ glutamine, $50 \mathrm{U} / \mathrm{ml}$ penicillin, $50 \mu \mathrm{g} / \mathrm{ml}$ streptomycin, and $6 \mathrm{~mm}$ glucose. After $2 \mathrm{~d}$ in culture the medium was changed to one containing $2 \%$ CEE. Cells were fed twice weekly thereafter. Media, horse serum, and antibiotics were purchased from Gibco (Grand Island, NY). CEE was prepared as a saline extract of 10-d-old chick embryos.

Electrophysiology. Between 3-14 d in culture, neurons were studied using gigaseal whole-cell voltage-clamp techniques (Hamill et al., 1981) with a List EPC 7 patch-clamp amplifier. At the time of study, motoneurons bearing a fluorescent label were identified using a Leitz inverted microscope equipped with interference contrast and epifluorescence optics (Fig. 1).

For recording purposes, the nutrient medium was replaced with a solution containing (in mM): $140 \mathrm{NaCl}, 5 \mathrm{KCl}, \mathrm{i} \mathrm{MgCl}_{2}, 3 \mathrm{CaCl}_{2}, 10$ glucose, $10 \mathrm{HEPES}$, and $1 \mu_{\mathrm{M}} \mathrm{TTX}, \mathrm{pH}$ 7.3. In some experiments, magnesium was omitted. Recording pipettes routinely contained (in mm): $140 \mathrm{CsCl}, 4 \mathrm{NaCl}$, 5 EGTA-NaOH, $0.5 \mathrm{CaCl}_{2}, 10 \mathrm{HEPES}, \mathrm{pH}$ 7.3. Excitatory amino acids were dissolved in the bathing solution and applied to neurons by pressure ejection (1-5 psi) from pipettes (1-2 $\mu \mathrm{m}$ tip diameter) positioned within $50 \mu \mathrm{m}$ of the cell body. For competition studies, known concentrations of agonists were placed in the same pipette. Excitatory amino acid antagonists were dissolved in bathing media and applied by bath perfusion. All recording was performed at room temperature $\left(24^{\circ} \mathrm{C}\right)$. All chemicals, with the exception of D-APV (Cambridge Research Chemicals) and AMPA (generous gift of Dr. Thomas Lanthorn), were purchased from Sigma Chemical Co. (St. Louis, MO).

Fluctuation analysis. For steady-state fluctuation analysis, agonistgated currents were analyzed with a PDP $11 / 23$ computer. One channel was used to record low-gain DC signals for determination of mean currents, while a second channel, filtered at $1 \mathrm{kHz}$ (8-pole low-pass filter; Frequency Devices, Haverhill, MA) to prevent aliasing errors, was used to analyze AC-coupled $(0.5 \mathrm{~Hz}, 2$-pole high-pass filter) current fluctuations. A smooth power spectral estimate was obtained by averaging transforms of 16-32 episodes of 512 point samples digitized at a rate of $2.5 \mathrm{kHz}$ yielding spectra in the bandwidth $4.88 \mathrm{~Hz}-1.25 \mathrm{kHz}$. The background spectrum of current fluctuations in the absence of agonist was subtracted from that obtained in the presence of drug. The resulting spectrum was fit with a computer generated Lorentzian function of the form: $S(f)=S(0) /\left[1+\left(f / f_{c}\right)^{2}\right]$. The mean channel open time, $\tau$, was calculated from the relation: $\tau=1 / 2 \pi_{f,}$, where $f_{c}$ is the corner 

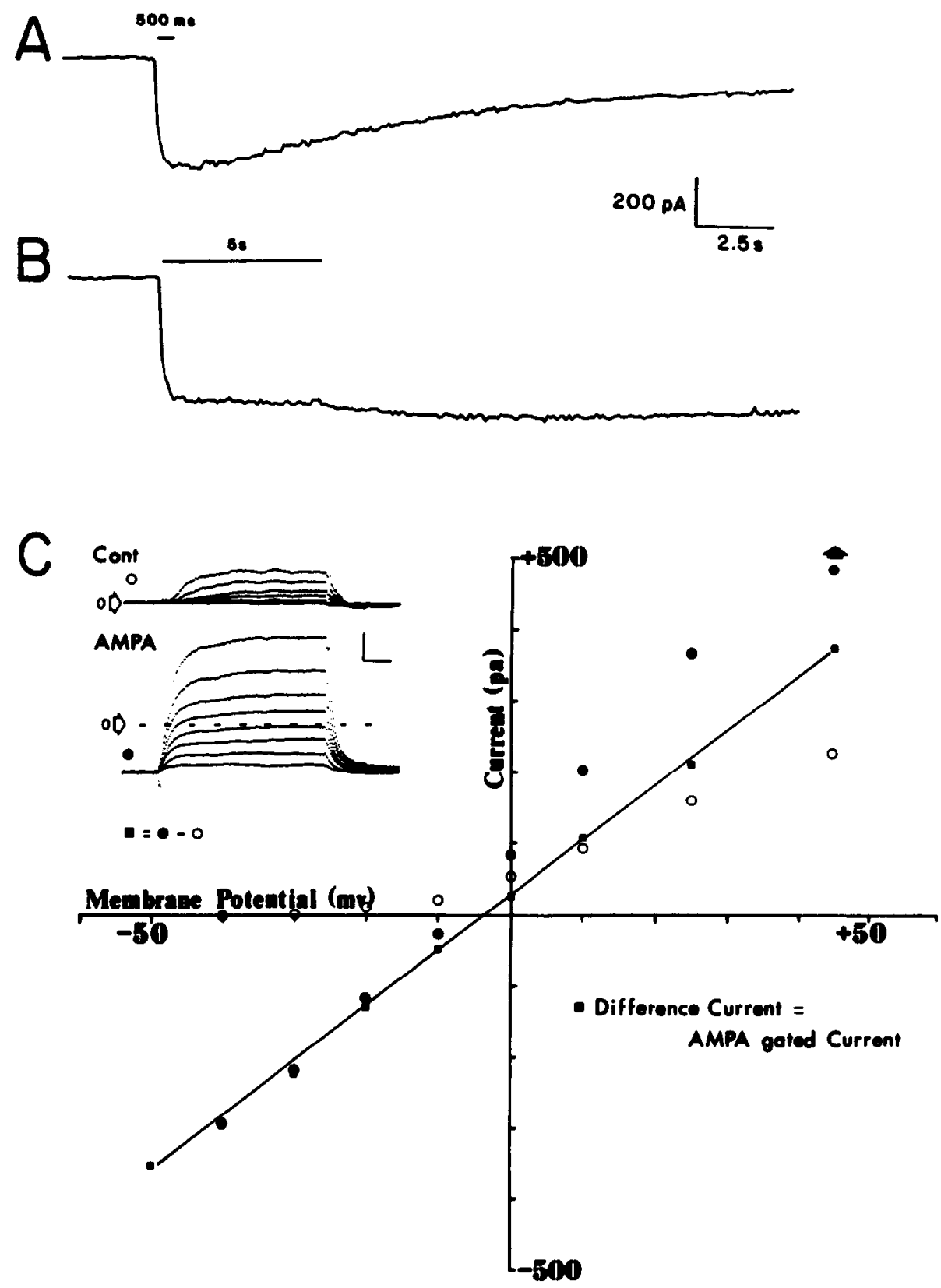

Figure 2. A, Macroscopic current recorded during a $500 \mathrm{msec}$ pressure application of $1 \mathrm{~mm}$ AMPA to an identified motoneuron voltage-clamped at $-50 \mathrm{mV}$. Note the prolonged nature of the current, outlasting the period of drug application. $B$, Lack of desensitization in response to a $5 \mathrm{sec}$ application of 1 mM AMPA. $C$, Current-voltage relation of AMPA-induced currents. Identified neurons were voltage-clamped at $-50 \mathrm{mV}$ and $50 \mathrm{msec}$ depolarizing steps to $-40,-30,-20,-10,0,+10,+25$, and $+45 \mathrm{mV}$ were applied before (open circles) and during (solid circles) administration of $100 \mu \mathrm{M}$ AMPA. Leakagesubtracted current traces are shown in insert. Difference current (solid squares), which represents the AMPA-activated current, shows a linear $I-V$ relationship. Similar linear $I-V$ curves were found when neurons were held at various membrane potentials over the range of -85 to $+40 \mathrm{mV}$ during repeated 500 msec applications of AMPA (data not shown).

frequency for the Lorentzian spectrum. The single-channel conductance was estimated by dividing the ratio of the variance of the current fluctuations to the mean current by the driving force (Neher and Stevens, 1977).

Single-channel recording. Kainate- and quisqualate-gated singlechannel currents were recorded from outside-out membrane patches at a holding potential of $-50 \mathrm{mV}$ with Sylgard-coated pipettes. These studies were conducted using the standard external and internal solutions, with the exception that the external solution also contained 200 $\mu \mathrm{M}$ D-APV to block NMDA-type responses that might arise from spontaneous release of glutamate or aspartate in the culture. Agonists were applied to patches by bath perfusion or by diffusion from blunt pipettes positioncd ncar the patch. Singlc-channel currents were filtered at $1 \mathrm{kHz}$ and recorded on FM tape (DC, $2.5 \mathrm{kHz}$ bandwidth). Channel open times were analyzed off-line using an event-driven analysis program (Kegel et al., 1985; pCLAMP, Axon Instruments, Burlingame, CA). The criterion for a valid event was defined as a half-maximal threshold crossing for a minimum of $200 \mu \mathrm{sec}$. This combined with the low-pass filter gave an approximate minimum dwell time resolution of $700 \mu \mathrm{sec}$. Exponential fitting to the dwell time histograms was done using the
Lavenberg-Marquardt algorithm with sum-squared error as the measure.

\section{Results}

\section{AMPA physiology/pharmacology}

Identitied chick motoneurons voltage-clamped near their resting membrane potential $(-50 \mathrm{mV})$ respond to brief applications of AMPA with an inward going current (Fig. 2A). At all concentrations studied, the AMPA-induced current showed no evidence of desensitization during prolonged $(5 \mathrm{sec})$ administration (Fig. 2B) and exhibited a linear current-voltage relationship over the range of -85 to $+40 \mathrm{mV}$ with a reversal potential near $0 \mathrm{mV}$ (Fig. 2C). The mean interpolated reversal potential in 6 neurons was $+2.7 \pm 1.7 \mathrm{mV}$ (mean $\pm \mathrm{SEM}$ ). One interesting feature of AMPA currents is their prolonged duration. As depicted in Figure $2 B$, the response to a $5 \mathrm{sec}$ application of $1 \mathrm{~mm}$ 


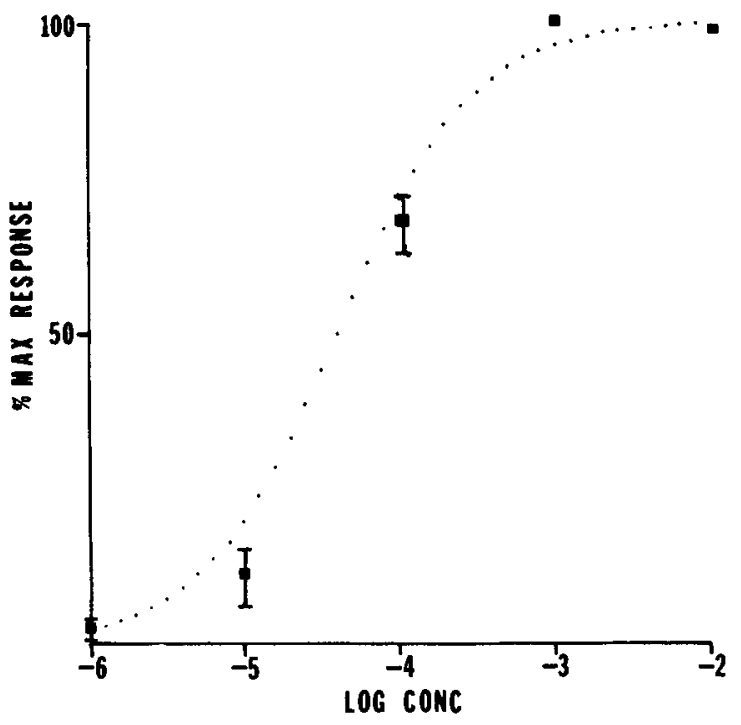

Figure 3. Dose-response curve for AMPA-induced currents. Neurons were voltage-clamped at $-50 \mathrm{mV}$ and $500 \mathrm{msec}$ pressure applications of AMPA were administered. Responses were normalized with respect to the response at $1 \mathrm{mM}$ AMPA. The continuous line is a Langmuir isotherm equation, Response $=I_{\max }\left(\{\mathrm{AMPA}\} /\{\mathrm{AMPA}\}+\mathrm{ED}_{50}\right)$, fit with $\mathrm{ED}_{50}=40 \mu \mathrm{M}$. The data presented are from cells studied with 2 or more concentrations of AMPA and represent the mean \pm SEM from 5 cells per concentration except for $10 \mathrm{mM}$, which is from 3 cells.

AMPA persisted at its peak level long after the drug application pulse was terminated. In some experiments the inward current pcrsisted at its peak level for more than $1 \mathrm{~min}$ after a $5 \mathrm{sec}$ application before decaying back to the baseline holding current. Among the excitatory amino acids studied to date, AMPA has the longest duration of action.

Applications of AMPA at concentrations between $1 \mu \mathrm{M}$ and $10 \mathrm{~mm}$ produced a dose-dependent increase in current when neurons were clamped at $-50 \mathrm{mV}$ (Fig. 3). The half-maximal concentration for this effect was $40 \mu \mathrm{M}$. The experimental points comprising the dose-response curve were described by a simple bimolecular reaction and showed no evidence of cooperativity.

AMPA currents were insensitive to bath applications of the selective NMDA blocker, APV (100 $\mu \mathrm{M}-1 \mathrm{mM}$; Fig. 4A). At all holding potentials $(-85$ to $+40 \mathrm{mV})$, responses to AMPA were unaffected by external magnesium concentration over the range of 0 (no added magnesium) to $1 \mathrm{~mm}$. Glutamate diethyl ester (GDEE, 1-10 mM), which has been reported to block quisqualate responses selectively in other systems (Davies and Watkins, 1979) also had no effect on AMPA responses (Fig. 4B). The nonselective excitatory amino acid antagonist, kynurenate, decreased AMPA currents by $54 \pm 4 \%$ at a concentration of $1 \mathrm{mM}$ $(n=5$; Fig. 4C).

\section{AMPA competes with kainate and quisqualate}

Previous studies indicated that kainate and quisqualate compete for the same receptor on identified chick motoneurons (O'Brien and Fischbach, 1986a). Because AMPA exhibited physiological responses similar to kainate and quisqualate (i.e., a linear current-voltage relation, a nondesensitizing current and insensitivity to APV and magnesium), we examined whether AMPA shared a common mechanism with these other agonists. In our experiments, the peak current induced by a saturating concentration of AMPA $(1 \mathrm{mM})$ at a holding potential of $-50 \mathrm{mV}$ was $372 \pm$
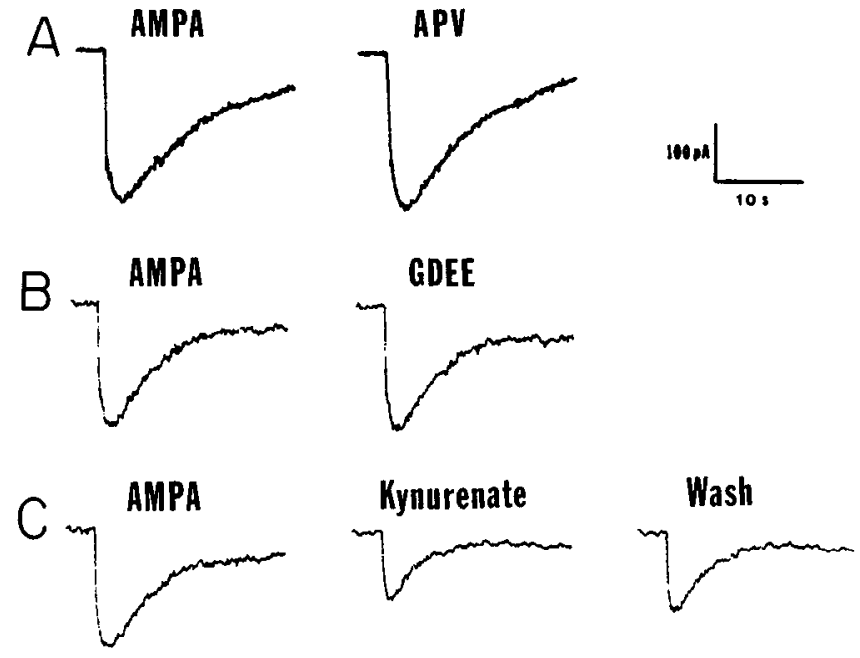

Figure 4. Effect of excitatory amino acid antagonists on AMPA currents. Neurons were voltage-clamped at $-50 \mathrm{mV}$ and $1 \mathrm{mM}$ AMPA was applied for $500 \mathrm{msec}$ (solid circles). Antagonists were dissolved in external recording solution and administered to neurons by bath at a concentration of $1 \mathrm{mM}$. $A$, APV; $B$, GDEE; $C$, kynurenate. Only partial reversal of kynurenate suppression was observed after $5 \mathrm{~min}$ of washout.

$40 \mathrm{pA}(n=41)$. This was intermediate between the maximal currents induced by saturating concentrations of kainate $(1 \mathrm{mM}$; $727 \pm 153 \mathrm{pA}, n=15)$ and quisqualate $(10 \mu \mathrm{M} ; 207 \pm 23 \mathrm{pA}$, $n=5$; concentrations for kainate and quisqualate as reported by O'Brien and Fischbach, 1986a). If AMPA shares a common mechanism with kainate and quisqualate, then the current produced by a combination of saturating concentrations of AMPA and either of the other 2 agonists should approximate the arithmetic mean of the response to saturating concentrations of either agonist alone. If the agents are acting at separate receptor-channel complexes, the combination should give an approximately additive response, assuming no interaction between the sites. In neurons tested in this fashion, the combination of saturating concentrations of AMPA and quisqualate produced currents that were intermediate to those produced by either agonist alone (Fig. $5 A$ ). The same lack of summation was found following simultaneous administration of AMPA and kainate (Fig. $5 B$ ). Data from a series of neurons studied in this fashion are summarized in Figure $5 C$. The current produced by AMPA and either quisqualate or kainate approached the arithmetic average of the currents induced by the agonists alone. In contrast, coapplication of AMPA (1 mM) with the selective NMDA agonist, L-aspartate ( $1 \mathrm{mM}$ ) gave a response larger than the response to either agonist alone (Fig. $5 \mathrm{C}$ ). These data suggest that AMPA shares a common mechanism with kainate and quisqualate but does not interact with NMDA receptors.

\section{AMPA, kainate and quisqualate have different probabilities of channel opening}

Despite having similar physiology, there are differences in efficacy among the non-NMDA agonists, with kainate always giving the largest response at saturation and quisqualate always giving the smallest (Table 1). The macroscopic current recorded under whole-cell voltage clamp is a product of the number of available channels, the probability of channels being open, and the single-channel current. Since the 3 agonists show physiological competition, it is unlikely, for a given cell, that the num- 

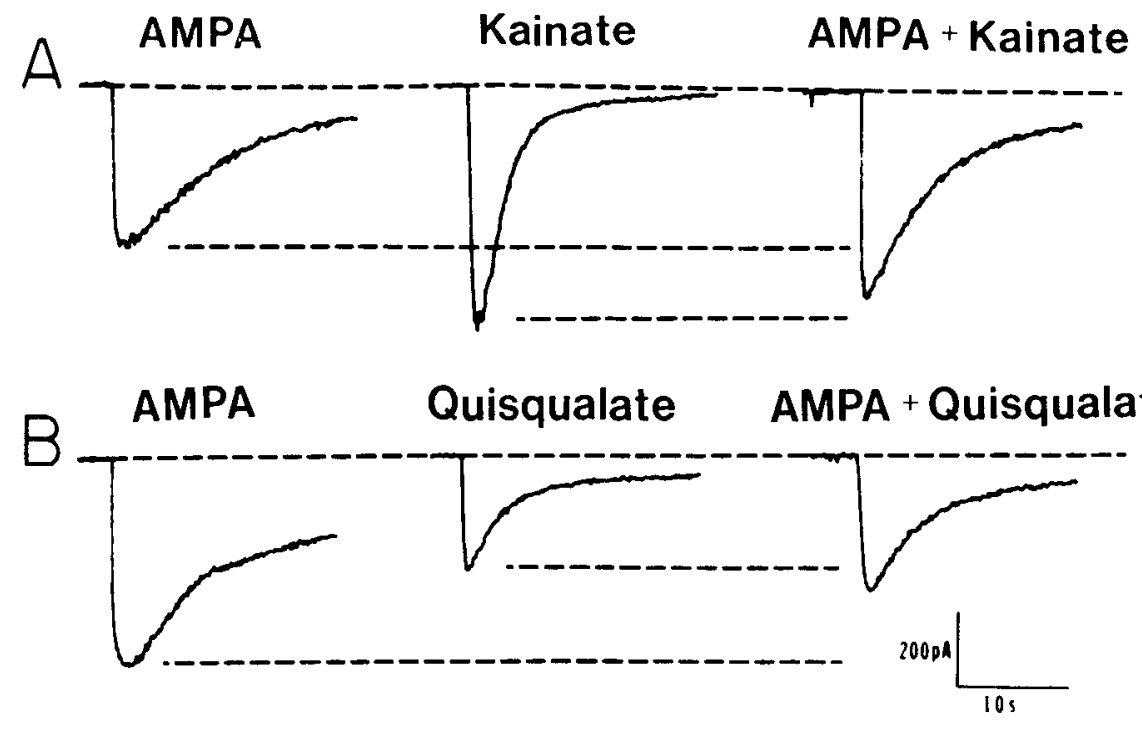

Figure 5. Competition expcriments of AMPA with kainate or quisqualate. Neurons were voltage-clamped at -50 $\mathrm{mV}$ and agonists were applied for 500 msec. $A$, Response to saturating concentrations of AMPA (1 mM), kainate (l $\mathrm{mM}$ ), and a combination of both compounds. $B$, Similar experiment using $1 \mathrm{mM}$ AMPA and a saturating concentration of quisqualate $(10 \mu \mathrm{M}) . C$, Histogram displaying the results of competition experiments. The simultaneous application of 2 non-NMDA agonists-AMPA and kainate (left) or AMPA and quisqualate (middle)-rcsults in intermediate responses, while coapplication of AMPA with the NMDA-selective agonist aspartate (1 mM) results in a response greater than that due to either agonist alone. The data displayed are normalized with respect to the response to $1 \mathrm{mM}$ AMPA (mean $\pm \mathrm{SEM}$ ). The numbers in the lower part of the figure are the number of cells studied. Abbreviations: $A$, AMPA; $K$, kainate; $A / K$, combination of AMPA and kainate; $Q$, quisqualate; $A / Q$, combination of AMPA and quisqualate; $A S P$, aspartate; $A / A S P$, combination of AMPA and aspartate.

ber of channels activated accounts for differences in peak response. To investigate differences in single-channel current, we analyzed current fluctuations produced by low concentrations of these 3 agonists. The power spectra of AMPA induced currents were fit by single Lorentzian functions and gave a primary single-channel conductance of $18 \pm 3.4 \mathrm{pS}(n=10$; Fig. 6). Kainate and quisqualate spectra were also fit by single Lorentzian curves and had primary single-channel conductances near $20 \mathrm{pS}$ (Table 1).

Given the competition among AMPA, kainate, and quisqualate and the similarity in single-channel current, it is likely that differences in the probability of channels being open accounts for differences in peak response. This probability depends on the frequency of channel opening and the mean channel open time. Since previous studies at the endplate $\mathrm{ACh}$ receptor have shown that more effective agonists exhibit longer channel open times (Katz and Miledi, 1973), we expected the most efficacious agonist, kainate, to have the longest mean channel duration. Instead, we found that kainate has the shortest channel open time, being on average half that for either AMPA or quisqualate (Table 1). Because our measures of channel open time were obtained by fluctuation analysis at low agonist concentrations, while differences in maximal response were obtained at saturating concentrations, we examined whether the channel open time for kainate increases with concentration. In outside-out patches, there was no difference in the kainate channel open

Table 1. Properties of selective non-NMDA agonists

\begin{tabular}{llllr} 
Agonist & $\begin{array}{l}\text { Open time } \\
(\mathrm{msec})\end{array}$ & $\begin{array}{l}\text { Conductance } \\
(\mathrm{pS})\end{array}$ & $\begin{array}{l}\text { Peak response } \\
(\mathrm{pA})\end{array}$ & $\begin{array}{l}\mathrm{ED}_{50} \\
(\mu \mathrm{M})\end{array}$ \\
\hline AMPA & $5.9 \pm 0.4$ & $18 \pm 3$ & $372 \pm 35$ & 40 \\
Quisqualate & $5.0 \pm 0.5$ & $20 \pm 2$ & $207 \pm 23$ & 1 \\
Kainate & $2.7 \pm 0.1$ & $21 \pm 2$ & $727 \pm 153$ & 80
\end{tabular}

The mean open time and conductance were estimated from analysis of current fluctuations. Values presented are mean \pm SD for $10 \mu \mathrm{M}$ AMPA $(n=10), 2 \mu \mathrm{M}$ quisqualate $(n=5), 20 \mu \mathrm{M}$ kainate $(n=15)$ at a holding potential of $-50 \mathrm{mV}$. Peak response estimates (mean \pm SEM) were obtained from 500 msec pressure applications of saturating concentrations of the agonists [AMPA, $1 \mathrm{mM}(n=41)$; quisqualate $10 \mu \mathrm{M}(n=5)$; kainate $1 \mathrm{mM}(n=15)$ ] at a holding potential of -50 $\mathrm{mV}$. The $\mathrm{ED}_{s 0}$ for AMPA is derived from dose-response data presented in this study, while that for quisqualate and kainate is from results obtained in identified motoneurons by O'Brien and Fischbach (1986a). 

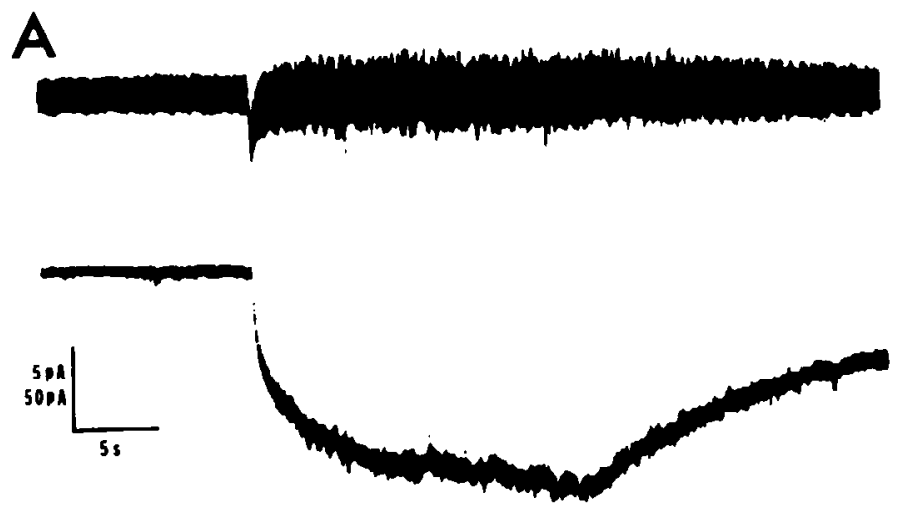

B

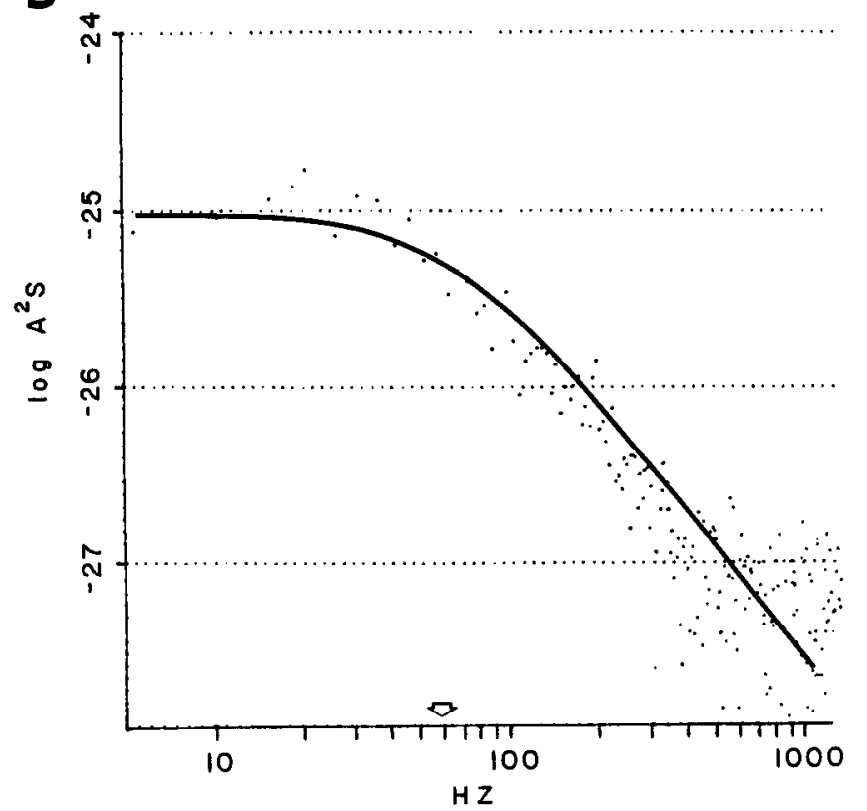

Figure 6. Steady-state fluctuation analysis of currents induced by AMPA. $A$, High-gain AC-coupled signal (top) and DC current (bottom) produced by a $20 \mathrm{sec}$ pressure application of AMPA $(10 \mu \mathrm{M})$. $B$, Power spectra of current fluctuations induced by AMPA. Solid line represents a single Lorentzian curve fitted to the spectral estimate. The arrow represents the corner frequency $(59 \mathrm{~Hz})$. Qualitatively similar results were obtained for kainate $(20 \mu \mathrm{M})$ and quisqualate $(2 \mu \mathrm{M})$.

time at low $(20 \mu \mathrm{M})$ or high (1 mM) concentrations (Fig. 7). At a concentration of $20 \mu \mathrm{M}$, the mean kainate channel open time is $1.4 \mathrm{msec}$ ( $n=2696$ events, 4 patches), while at $1 \mathrm{mM}$ the channel open time is $1.3 \mathrm{msec}(n=5970$ events, 4 patches). The primary conductance for the kainate gated channel was near $20 \mathrm{pS}$ at both concentrations. As is true in other systems, multiple conductance kainate events were seen (Cull-Candy and Usowicz, 1987; Jahr and Stevens, 1987). However, more than $90 \%$ of events fell in the range of 18-22 pS under the recording conditions used in this study.

Although we found no concentration-dependent change in the kainate channel open time, inspection of current fluctuations at low and high agonist concentrations reveals concentration-dependent differences among the agonists. AMPA and quisqualate exhibit a peak of current fluctuations at both low and high doses at the peak of the macroscopic response (Fig. 8, $A, B$ ). At low concentrations, the peak in kainate current fluctuations also occurs at the peak of the macroscopic response. However, at saturation, the peak amplitude of kainate current fluctuations occurs after the peak of the macroscopic response, at a time when the macroscopic current is decaying (Fig. $8 \mathrm{C}$ ). Such an effect is expected of agents having a very high probability of open channels at the peak of the response (Sigworth, 1980) and supports the hypothesis that the kainate open channel probability is greater than AMPA or quisqualate at saturation.

To quantitate relative differences in open channel probability, we examined single outside-out patches in the presence of saturating concentrations of kainate and quisqualate, the agonists showing the largest differences in macroscopic current. Figure $9 A$ shows a continuous recording from an outside-out patch exposed to $1 \mathrm{~mm}$ kainate (solid line) and then to $10 \mu \mathrm{M}$ quisqualate (dotted line). Visual inspection of these recordings indicates that the channels are opened more frequently by kainate than quisqualate. Further analysis of these data indicate that the average percentage of time the channels are open for kainate is $6 \%$ compared with $1 \%$ for quisqualate (Fig. $9, B, C$ ). Given the observation that the kainate channel open time is only half that of quisqualate, the actual probability of kainate-liganded channels opening is 12 times greater than that for the same channels gated by quisqualate. This increase in channel opening is sufficient to explain the increased efficacy of kainate over other non-NMDA agonists.

\section{Discussion}

Prior studies suggest that AMPA is a potent glutamate analog acting selectively at quisqualate receptors (Hosli et al., 1983a; King et al., 1985). As chick motoneurons previously were found to express only 2 classes of receptors for excitatory amino acids (O'Brien and Fischbach, 1986a), we were interested in the actions of AMPA. We found that over all effective concentrations, AMPA acts in a fashion indistinguishable from kainate and quisqualate, producing an inward-going, nondesensitizing current at negative holding potentials. As is true of kainate and quisqualate, the current-voltage relationship for the AMPAgated conductance is linear, reversing near $0 \mathrm{mV}$. AMPA currents are also insensitive to the selective NMDA blocker APV and external magnesium ions. Furthermore, AMPA competes with kainate and quisqualate for the same receptor-channel complex. Based on our experiments, we find evidence for only 2 classes of excitatory amino acid receptors on chick motoneurons and no evidence that AMPA distinguishes between kainateand quisqualate-activated mechanisms in this system. It is possible that additional non-NMDA reccptors exist on chick motoneurons but were not detected using a physiological assay. However, if the non-NMDA agents act at multiple sites, it is likely that they compete for all such sites as O'Brien and Fischbach (1986a) previously demonstrated competition between kainate and quisqualate over the entire range of effective concentrations. At present, it is unclear whether this competition occurs at the level of the receptor or ion channel (Cull-Candy and Usowicz, 1987; Jahr and Stevens, 1987).

In other neuronal systems, the antagonist GDEE has been used to distinguish between kainate and quisqualate receptors (Haldeman and McLellan, 1972; McLellan and Lodge, 1979). The effects of GDEE on AMPA responses have been variable. In cat spinal cord neurons (Krogsgaard-Larsen et al., 1980) and rat spinal cord and brain-stem neurons (Hosli et al., 1983b), the actions of AMPA were blocked by GDEE, whereas in frog mo- 


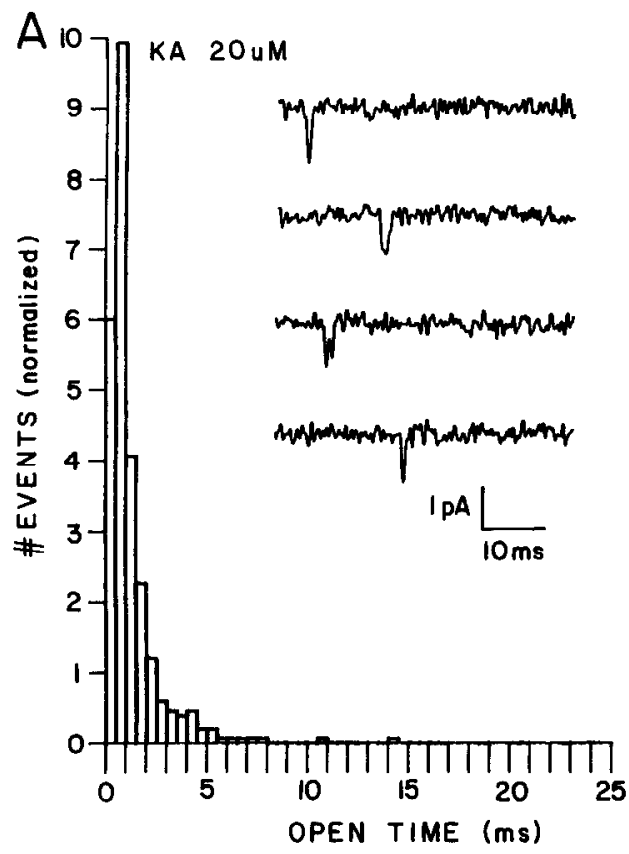

toneurons, GDEE had no effect (King et al., 1985). In our studies, GDEE, at concentrations in the millimolar range, was ineffective as an AMPA antagonist. Similarly, there is no effect of GDEE on either kainate or quisqualate responses (O'Brien and Fischbach, 1986a), indicating that in cultured chick motoneurons this agent is not useful for distinguishing possible non-NMDA receptor subtypes. On the other hand, the nonselective antagonist kynurenate had a modest ability to antagonize AMPA currents at concentrations in the millimolar range.

An interesting feature of AMPA is that the response far outlasts the duration of drug application. When applied for equal durations at equivalent concentrations, AMPA has the longest duration of action of any non-NMDA agonist tested (see Fig. $2 B$ ). Similar prolonged durations of action have been found in slice preparations (Krogsgaard-Larsen et al., 1980; King et al., 1985). The mechanisms underlying this prolonged action are unclear but cannot be accounted for by the small differences in channel open time. Similarly, differences in high-affinity uptake among the agonists are unlikely to explain the prolonged duration as kainate, the agent with the briefest duration of action, is either not taken up or is weakly affected by the uptake system (Johnston et al., 1979, 1980; Garthwaitc, 1985). It is possible that buffered diffusion of agonists could account for the differences. That is, certain agonists may be taken up by cells in the vicinity of a recorded neuron and slowly released, leading to prolonged activation of receptors. Alternatively, it is possible that the binding of AMPA to its receptor is relatively long compared with the duration of channel opening, and as a result there could be multiple reopening of the channel during a single receptor occupancy. Finally, it is possible that the prolonged phase of response is due to a mechanism unrelated to channel opening. Precedence for such an action is found in autonomic ganglia, where $\mathrm{ACh}$ produces prolonged responses in which the later components occur by mechanisms differing from earlier components (Jan et al., 1979; North and Tokimasa, 1983).

The marked differences in efficacy among AMPA, kainate, and quisqualate are due to differences in the frequency of chan-
Figure 7. Kainate mean channel open time does not increase with agonist concentration. $A$ and $B$, Open-time histograms for $20 \mu \mathrm{M}(A)$ and $1 \mathrm{mM}(B)$ kainate applied to outside-out membrane patches. Insets, Examples of fast sweeps of kainate-gated channels at each concentration. The open time was 1.4 $\mathrm{msec}(n=2696)$ for $20 \mu \mathrm{M}$ and $1.3 \mathrm{msec}$ $(n=5970)$ for $1 \mathrm{~mm}$ calculated from a monoexponential fit to the channel open time distribution by a minimum-sum squared-error criterion. Mean open times determined as the arithmetic average of all open times for 3 successive sequences of 2000 events for $1 \mathrm{~mm}$ kainate were $1.44 \pm 1.64,1.28 \pm 2.37$, and $1.33 \pm 1.36 \mathrm{msec}$ (mean $\pm \mathrm{SD}$ ), suggesting stationary behavior of the channel.

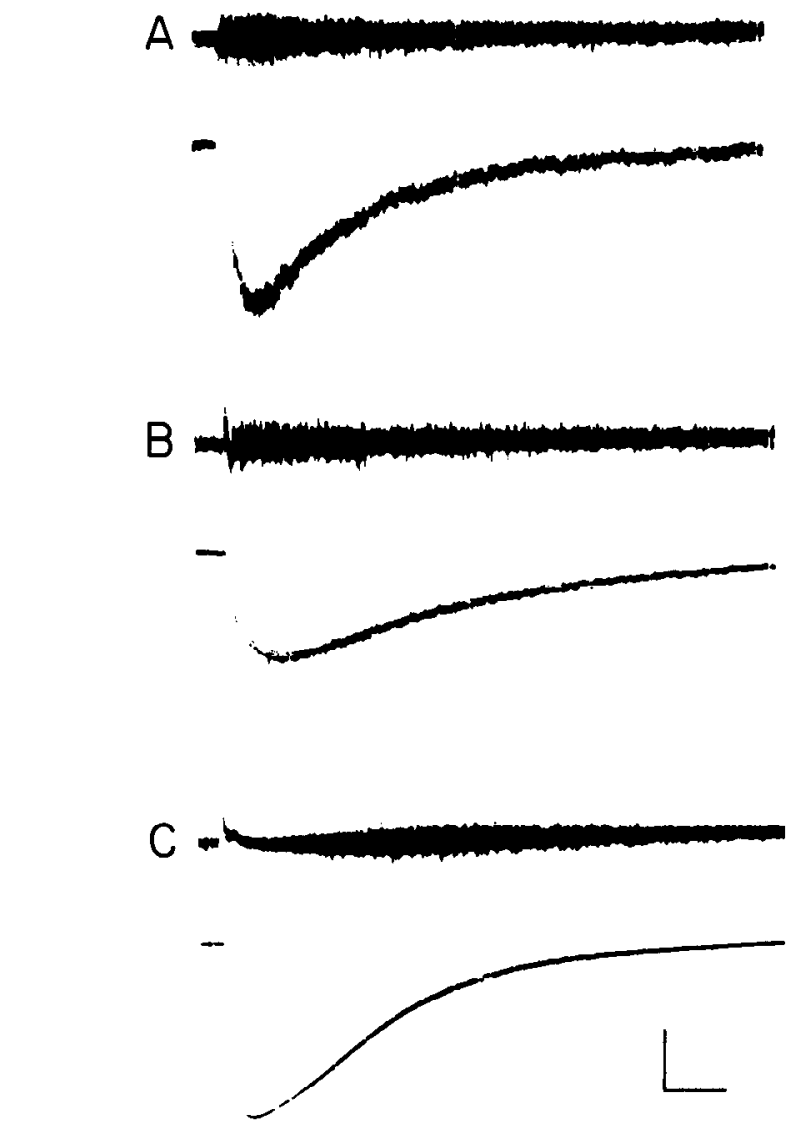

Figure 8. Current fluctuations and peak macroscopic response produced by saturating concentrations of quisqualate, AMPA, and kainate. High-gain AC coupled signal (upper trace) and DC current (lower trace) induced by $500 \mathrm{msec}$ pressure applications of quisqualate $(10 \mu \mathrm{M}, A)$, AMPA ( $1 \mathrm{~mm}, B)$ or kainate ( $1 \mathrm{~mm}, \mathrm{C})$. Note that the peak of the AMPA or quisqualate $\mathrm{DC}$ response corresponds to the peak current fluctuations, whereas the peak kainate fluctuations occur after the peak of the DC response. Calibration bar: $5 \mathrm{pA}$ (for all upper traces); $100 \mathrm{pA}(A), 200$ pA $(B), 400$ pA $(C), 5$ sec. 
Figure 9. Channels have a higher probability of being open in the presence of kainate. $A$, Slow chart recording from a single outside-out patch exposed to kainate, $1 \mathrm{~mm}$ (left), and then quisqualate, $10 \mu \mathrm{M}$. Agonists were applied to the patch by diffusion from blunt pipettes positioned within $10 \mu \mathrm{m}$ of the patch. Of note is the increased frequency of channel opening in the presence of kainate. $B$ and $C$, Amplitude histograms for channel openings produced by kainate $(B)$ or quisqualate $(C)$ from the same patch as depicted in $A$. Continuous epochs of data were sampled at $200 \mu \mathrm{sec} /$ point, and the distribution of channel amplitudes was plotted. The area under the histogram represents the relative duration that channels spent in any given state. The analysis shown represents $5.12 \mathrm{sec}$ of data taken from a longer record for kainate and quisqualate. In the example shown the channels spent most of the time closed $(0 \mathrm{pA})$. The relative time that channels are open is 0.12 for kainate compared with 0.01 for quisqualate. Analysis of 5 such segments of data for this patch revealed a relative time that any channel was open of 0.06 for kainate compared with 0.01 for quisqualate. Similar results were obtained from 2 other patches studied in this fashion.
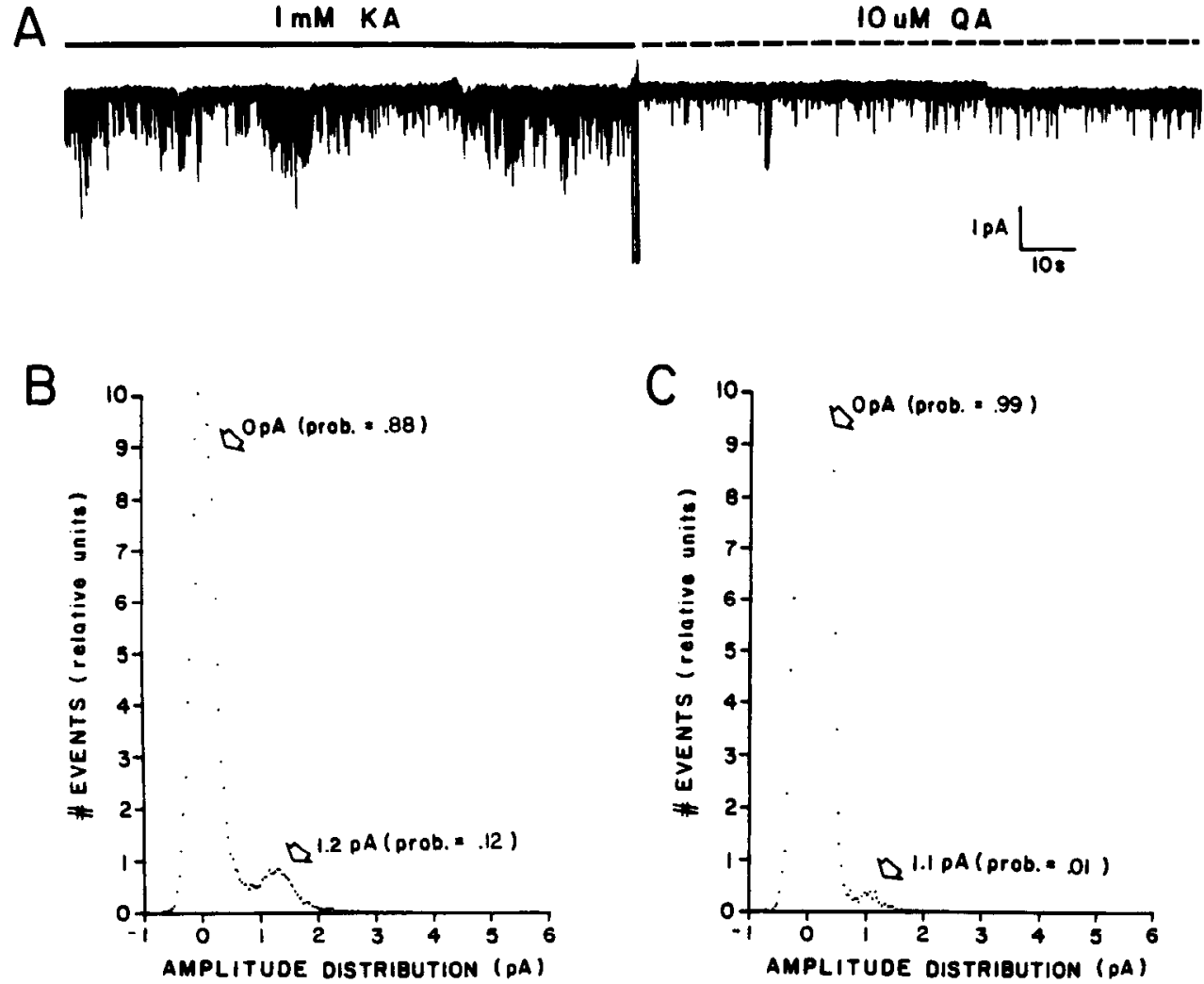

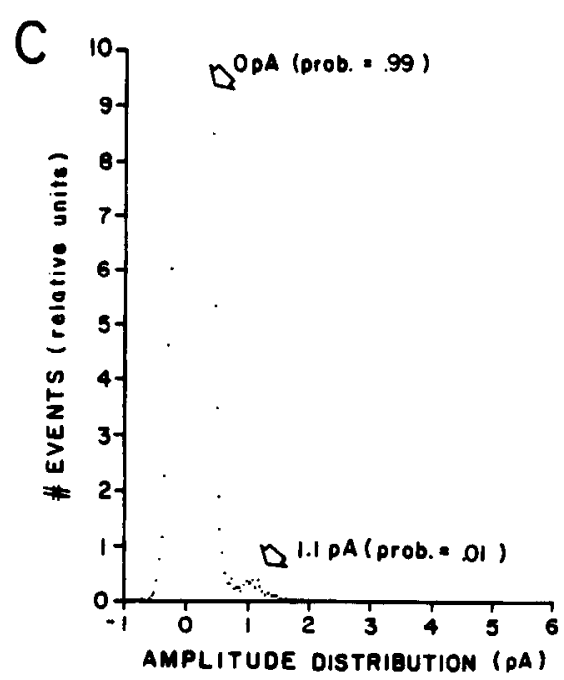

nel opening. We base this conclusion on observations that the 3 agonists compete for a common receptor-channel complex and have similar single-channel conductances. The observation that kainate exhibits the largest macroscopic current yet has the briefest channel open time suggests that this parameter does not account for the differences. In contrast to the action of glutamate at invertebrate neuromuscular junctions (Gration et al. 1981; Dudel and Franke, 1987), we found no evidence for a dosedependent increase in the channel open time that could account for kainate's increase in probability of being open at higher concentrations.

Our finding of a shorter channel open time for kainate compared to AMPA and quisqualate contrasts with earlier results for kainate and glutamate obtained from fluctuation analysis (O'Brien and Fischbach, 1986a). This discrepancy may be due to differences in voltage-clamp methods. In the present study we used cesium as the primary intracellular cation and included TTX in the external bath to improve spatial clamping. O'Brien and Fischbach used potassium as the internal cation in a lowcalcium/high-magnesium external solution. These differences in voltage-clamp methods may also account for differences in the single-channel conductances obtained in the 2 studies. We also found a discrepancy between channel open times using fluctuation analysis and single-channel recording, with the single-channel events being about half as long as the times estimated from noise. Similar differences between noise analysis and singlechannel recording have been reported in other systems (Jackson et al., 1982), particularly when single channels are recorded in the outside-out configuration (Trautman and Siegelbaum, 1983). An explanation based on the premise that fluctuation analysis measures "bursts" of channel activity, whereas single-channel recording measures individual channel events does not hold since we found no evidence for bursting (rapid flickering during an open event) of the kainate-gated channel even at saturating agonist concentrations. Despite differences between single-channel recording and fluctuation analysis, it still holds, with either method, that kainate has a channel open time about half that of quisqualate (Zorumski and Yang, unpublished observations).

It is possible that there are other differences among nonNMDA agonists not detected in the present study. One area of concern is whether the lower efficacy agonists, AMPA and quisqualate, have properties that decrease responses at high concentrations. At the nicotinic $\mathrm{ACh}$ receptor, some agonists have a lower efficacy becausc they not only open, but also block, the ion channel (Adams and Sakmann, 1978). In goldfish retinal cells, excitatory amino acid agonists with lower efficacy (glutamate and quisqualate) produce use-dependent decrements in response at high concentrations, whereas the most potent agonist, kainate, does not (Ishida and Neyton, 1985). This observation could be the result of dose-dependent desensitization or agonist-induced ion channel block. Although in chick motoneurons, using conventional pressure application methods, we have not found use-dependent decrements in non-NMDA responses at concentrations up to saturation (Zorumski and Fischbach, 1985), it is possible that at higher concentrations desensitization or channel blockade may occur and thus reduce agonist efficacy (Adams, 1981). Indirect support for this hypothesis is provided by recent studies in chick spinal cord (Vyklicky et al., 1986) and rat hippocampal neurons (Kiskin et al., 1986), in which concentrations of quisqualate greater than $20 \mu \mathrm{M}$ produce responses similar to those reported in the goldfish retina. An important difference between our results and the studies demonstrating use-dependent decreases in quisqualate currents lies in the drug delivery systems. The studies described above have used high-flow rapid perfusion techniques and not the slower pressure applications used in the present study. It may be that 
certain effects of non-NMDA agonists depend not only on the concentration of the agonist but also on the suddenness with which the agonist is applied to neurons (Trussel and Fischbach, 1987).

Finally, our results may shed light on the toxic properties of non-NMDA agonists. In addition to stimulating neurons, these agents are known to damage neurons during periods of prolonged exposure (Olney, 1978). This toxic action is thought to be a product of the ion flux and fluid shifts accompanying excitation (Price et al., 1985; Rothman, 1985). The prolonged response of neurons to relatively brief applications of AMPA may account for this agent's marked potency as a neurotoxin (Morgan, 1987). Similarly, the large, nondesensitizing response induced by kainate may underlie the marked neuron-damaging properties of this agent.

\section{References}

Adams, P. R. (1981) Acetylcholine receptor kinetics. J. Membrane Biol. 58: 161-174.

Adams, P. R., and B. Sakmann (1978) Decamethonium both opens and blocks endplate channels. Proc. Natl. Acad. Sci. USA 75: 29942998.

Cull-Candy, S. G., and M. M. Usowicz (1987) Multiple conductance channels activated by excitatory amino acids in cerebellar neurons. Nature 325: 525-528.

Davies, J., and J. C. Watkins (1979) Selective antagonism of amino acid-induced and synaptic excitation in the cat spinal cord. J. Physiol. (Lond.) 297: 621-635.

Dudel, J., and C. Franke (1987) Single glutamate-gated synaptic channels at the crayfish neuromuscular junction: II. Dependence of channel open time on glutamate concentration. Pfluegers Arch. 408: 307-314.

Fagg, G. E., and A. Matus (1984) Selective association of N-methylaspartate and quisqualate types of L-glutamate receptors with brain postsynaptic densities. Proc. Natl. Acad. Sci. USA 81: 6876-6880.

Foster, A. C., and G. E. Fagg (1984) Acidic amino acid binding sites in mammalian neuronal membranes. Their characteristics and relationship to synaptic receptors. Brain Res. Rev. 7: 103-164.

Garthwaite, J. (1985) Cellular uptake disguises action of L-glutamate on N-methyl-D-aspartate receptors. Br. J. Pharmacol. 85: 297-307.

Gration, K. A. F., J. J. Lambert, R. Ramsey, and P. N. R. Usherwood (1981) Non-random openings and concentration-dependent lifetimes of glutamate gated channels in muscle membrane. Nature 291: $423-425$.

Haldeman, S., and H. McLellan (1972) The antagonist action of glutamic acid diethyl ester towards amino-acid induced and synaptic excitation of central neurons. Brain Res. 45: 393-400.

Hamill, O. P., A. Marty, E. Neher, B. Sakmann, and F. J. Sigworth (1981) Improved patch clamp techniques for high resolution current recording from cells and cell free membrane patches. Pfluegers Arch. 391: 85-100.

Honore, T., and M. Nielsen (1985) Complex structure of quisqualatesensitive glutamate receptors in rat cortex. Neurosci. Lett. 54: 27-32.

Honore, T., J. Lauridsen, and P. Krogsgaard-Larsen (1982) The binding of ${ }^{3} \mathrm{H}$-AMPA, a structural analogue of glutamic acid to rat brain membranes. J. Neurochem. 38: 173-178.

Hosli, E., P. Krogsgaard-Larsen, and L. Hosli (1983a) Binding sites for the glutamate analogue ${ }^{3} \mathrm{H}$-AMPA in cultured rat brainstem and spinal cord. Brain Res. 268: 177-180.

Hosli, L., E. Hosli, R. Lehmann, and P. Eng (1983b) Effects of the glutamate analogue AMPA and its interaction with antagonists on cultured rat spinal and brain stem neurons. Neurosci. Lett. 36: 5962.

Ishida, A. T., and J. Neyton (1985) Quisqualate and L-glutamate inhibit retinal horizontal cell responses to kainate. Proc. Natl. Acad. Sci. USA 82: 1837-1841.

Jackson, M. B., H. Lecar, D. A. Mathers, and J. L. Barker (1982) Single channel currents activated by gamma-aminobutyric acid, muscimol, and (-)pentobartibal in cultured mouse spinal cord neurons. J. Neurosci. 2: 889-894.

Jahr, C. E., and C. F. Stevens (1987) Glutamate activates multiple single channel conductances in hippocampal neurons. Nature 325: $522-525$.

Jan, Y. N., L. Y. Jan, and S. W. Kuffler (1979) A peptide as a possible transmitter in sympathetic ganglia of the frog. Proc. Natl. Acad. Sci. USA 76: 1501-1505.

Johnston, G. A. R., S. M. E. Kennedy, and B. Twitchin (1979) Action of the neurotoxin kainic acid on high affinity uptake of L-glutamic acid in rat brain slices. J. Neurochem. 32:121-127.

Johnston, G. A. R., D. Lodge, J. C. Bornstein, and D. R. Curtis (1980) Potentiation of L-glutamate and L-aspartate excitation of cat spinal neurons by stereoisomers of threo-3-hydroxyaspartate. J. Neurochem. $34 ; 241-243$.

Katz, B., and R. Miledi (1973) The characteristics of endplate noise produced by different depolarizing drugs. J. Physiol. (Lond.) 230:707717.

Katz, L. C., A. Burkhalter, and W. J. Dreyer (1984) Fluorescent latex microspheres as a retrograde neuronal marker for in vivo and in vitro studies of visual cortex. Nature 310:498-500.

Kegel, D. R., B. D. Wolf, R. E. Sheridan, and H. A. Lester (1985) Software for electrophysiological experiments with a personal computer. J. Neurosci. Methods 12: 317-330.

King, A. E., A. Nistri, and C. Rovira (1985) The excitation of frog motoneurons in vitro by the glutamate analogue DL- $\alpha$-amino-3-hydroxy-5-methyl-4-isoxazole-propionic acid (AMPA) and the effect of amino acid antagonists. Neurosci. Lett. 55: 77-82.

Kiskin, N. I., O. A. Krishtal, and A. Y. Tsyndrenko (1986) Excitatory amino acid receptors on hippocampal neurons: Kainate fails to desensitize them. Neurosci. Lett. 63: 225-230.

Krogsgaard-Larsen, P., T. Honore, J. J. Hansen, D. R. Curtis, and D. Lodge (1980) New class of glutamate agonist structurally related to ibotenic acid. Nature 284: 64-65.

Mayer, M. L., G. L. Westbrook, and P. B. Guthrie (1984) Voltage dependent block by magnesium of NMDA responses in spinal cord neurones. Nature 309: 261-263.

McLellan, H., and D. Lodge (1979) The antagonism of amino acid induced excitation of spinal neurons in the cat. Brain Res. 169:8390.

Morgan, I. G. (1987) AMPA is a powerful neurotoxin in the chicken retina. Neurosci. Lett. 79: 267-271.

Neher, E., and C. F. Stevens (1977) Conductance fluctuations and ionic pores in membranes. Annu. Rev. Biophys. Bioengin. 6: 345381 .

North, R. A., and T. Tokimasa (1983) Depression of calcium dependent potassium conductance in guinea pig myenteric plexus neurons. J. Physiol. (Lond.) 342: 253-266.

Nowak, L., P. Bregestovski, P. Ascher, A. Herbert, and A. Prochiantz (1984) Magnesium gates glutamate activated channels in mouse central neurones. Nature 307: 462-465.

O'Brien, R. J., and G. D. Fischbach (1986a) Characterization of excitatory amino acid receptors expressed by embryonic chick motoneurons in vitro. J. Neurosci. 6: 3275-3283.

O'Brien, R. J., and G. D. Fischbach (1986b) The isolation of embryonic chick motoneurons and their survival in vitro. J. Neurosci. 6: 3265-3274.

Olney, J. W. (1978) Neurotoxicity of excitatory amino acids. In Kainic Acid As A Tool In Neurobiology, E. M. McGeer, J. Olney, P. McGeer, eds., pp. 95-122, Raven, New York.

Price, M. T., J. W. Olney, L. Samson, and J. Labruyere (1985) Calcium influx accompanies but does not cause excitotoxin induced neuronal necrosis in retina. Brain Res. Bull. 14: 369-376.

Rothman, S. M. (1985) The neurotoxicity of excitatory amino acids is produced by passive chloride influx. J. Neurosci. 5: 1483-1489.

Sigworth, F. J. (1980) The variance of sodium current fluctuations at the node of Ranvier. J. Physiol. (Lond.) 307: 97-129.

Trautmann, A., and S. A. Siegelbaum (1983) The influence of membrane patch isolation on single acetylcholine channel current in rat myotubes. In Single Channel Recording, B. Sakmann and E. Neher, eds., pp. 473-480, Plenum, New York.

Trussell, L. O., and G. D. Fischbach (1987) Ionophoretic mapping of glutamate receptors on cultured chick spinal neurons. Soc. Neurosci. Abstr. 13: 384 .

Tsai, C., and J. Lehmann (1985) Quisqualate-type receptor sites labelled by ${ }^{3} \mathrm{H}$-AMPA - Lack of interaction with kainate. Soc. Neurosci. Abstr. 11: 109 .

Vyklicky, L., L. Vyklicky, F. Vyskocil, V. Vlachova, E. Ujec, and J. Michl (1986) Evidence that excitatory amino acids not only activate 
the receptor channel complex but also lead to a use-dependent block. Brain Res. 363: 148-151.

Zorumski, C. F., and G. D. Fischbach (1985) Differentiation of glutamate receptors based on desensitization. Soc. Neurosci. Abstr. 11: 105.
Zorumski, C. F., J. Yang, and G. D. Fischbach (1986) AMPA competes with kainate and quisqualate for glutamate G2 receptors on chick motoneurons. Soc. Neurosci. Abstr. 12: 56. 